\title{
Validation of Finite Element Analysis for a New External Finger Fixator to Correct Flexion Deformity - A Preliminary Result
}

\author{
H.S. Abd Rahman ${ }^{1}$, N.A. Abu Osman ${ }^{1}$, W.A.B. Wan Abas ${ }^{1}$, \\ T.S. Tunku Ahmad ${ }^{2}$ and E.S. $\mathrm{Ng}^{2}$ \\ ${ }^{1}$ Department of Biomedical Engineering, Faculty of Engineering, University of Malaya, Kuala Lumpur, Malaysia \\ ${ }^{2}$ Department of Orthopaedic Surgery, Faculty of Medicine, Kuala Lumpur, Malaysia
}

\begin{abstract}
The purpose of this study is to validate of a new external finger fixator components by using finite element analysis (FEA). The new external finger fixator consists of proximal, middle and distal phalanges support sections and means for rigidly connecting each support to a hinge and its corresponding attached to phalanx through the movements of flexion or extension. The results from the analysis found that the entire components of the fixator conform to the performance based on the requirements for general duty (500 $\mathrm{N}$ load applied on uniformly distributed load). This analysis shows that the new external fixator is able to restore full function and dynamic range of motion for patients with flexion deformity at the finger joints without failure.
\end{abstract}

Keywords - External finger fixator, Finite element analysis. flexion deformity, phalangeal bone

\section{INTRODUCTION}

Nowadays finite element analysis have been applied comprehensively with much success in the analysis of orthopaedic devices $[1,2,3,4,5]$. This kind of analysis will show how models can be constructed for the optimal solution of problems in contact mechanics. New development in this analysis is of supreme importance in the design for a new external finger fixator. Basically, this device relates generally to the treatment of contractures of a skeletal joint and more particularly to an external fixation device for allowing the fingers joint to be flexed or extended by the patient actively or passively and maintain its alignment in the natural axis of rotation for managing contractures or fractures of the fingers. A simple external finger fixator has been developed using small threaded pins which are inserted on both side of the respective bone, and which are connected by a fixation device comprising an articulated joint permitting, under medical supervision, a natural movement of the articulation. In order to affirm that the new fixator can actually withstand the subjected load (occurs from the stiffness joint), finite element analysis was produced to validate the performance of each component rather than on physical testing.

\section{Methodology}

\section{A. Geometry of the new external fixator}

The new external finger fixator consist of proximal, middle, and distal bracing segment which are adapted to stay in site relative to one another, for example as shown in Fig. 1. The design of the new external finger fixator was made through some revision to improve from the previous external finger fixator by Siow et al [6]. The geometry of each part was modeled by using Computer Aided Design (ProEngineer ${ }^{\circledR}$ version 3.0, PTC, Needham, MA) software and all parts for each component were imported into the solid modeller, ABAQUS/CAE 6.7 software enabling the finite element mesh to be generated for each component.

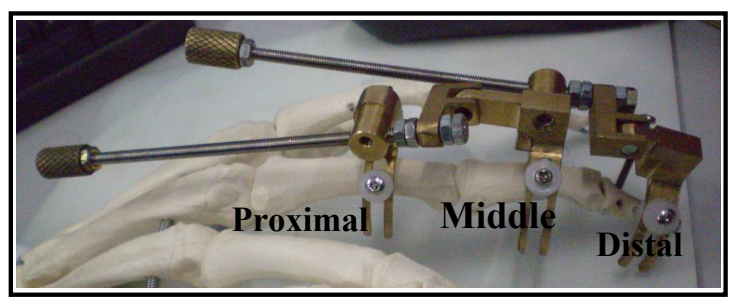

Fig. 1 The new external finger fixator consists of distal, middle, and proximal bracing segment which constructed on the skeleton model

\section{B. FE Mesh creation}

Compared with physical testing, FEA offers a number of significant advantages in parameter studies, such as in internal stress analysis [7]. Using currently available software, the analyst has great flexibility in meshing, but must set element sizes and fine-tuning throughout the domain. All assumptions need to be simple to keep the FE models controllable, not only from the viewpoint of the complex geometries, but also in view of the computational working environment. From Fig. 2, distal part was applied to an automatic procedure of FE meshing with a quadratic mesh element base from the geometry model build in CAD drawing. 


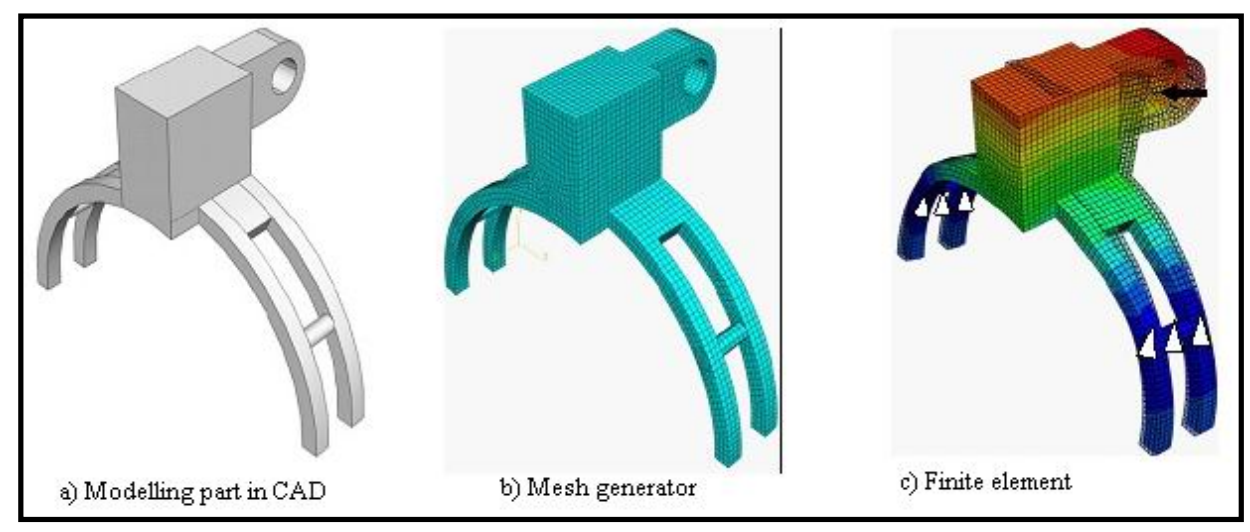

Fig. 2 Procedure from CAD modeling of distal part to finite elements.

\section{Loading and Material Properties}

To facilitate the convergence tests, simplified loading, constraints and material properties were applied. Each of the components was modeled as a linear geometry model and were represented by 4-noded quadrilateral elements which defined internally by ABAQUS 6.7. All the components were made from medical grade stainless steel $(316 \mathrm{~L})$ and their properties were included into the calculation (Table 1). Table 2 shows the loading, loading direction and where the constraint applied during analysis. In terms of the finger force, many researchers have studied tendon forces of the finger in various actions such as gripping and pinching $[8,9,10]$ using $2 \mathrm{D}$ or 3D biomechanical finger models. A uniformly distributed load of total $50 \mathrm{~N}$ is initially applied at each section which results at a maximum deflection. The

Table 1 Material Properties of the new external finger fixator

\begin{tabular}{ll}
\hline Properties & 316 steel \\
\hline Density $\left(\mathrm{kg} / \mathrm{m}^{3}\right)$ & 8000 \\
Tensile strength, Ultimate (MPa) & 515 \\
Tensile strength, Yield (MPa) & 205 \\
Modulus of Elasticity (GPa) & 193 \\
Poisson's Ratio & 0.25 \\
\hline
\end{tabular}

Table 2 Loading and constraint for each part of a new external finger fixator

\begin{tabular}{llcll}
\hline No & \multicolumn{1}{c}{ Part } & $\begin{array}{c}\text { Loading } \\
(\mathrm{N})\end{array}$ & $\begin{array}{c}\text { Constraint } \\
(\mathrm{x}=0 \mathrm{y}=0 \mathrm{z}=0)\end{array}$ & $\begin{array}{c}\text { Loading direction } \\
\text { (L-section) }\end{array}$ \\
\hline 1 & Distal & 50 & C - section & z-axis direction \\
2 & Rod holder & 50 & D - section & z-axis direction \\
3 & Middle & 50 & C - section & z-axis direction \\
4 & Proximal & 50 & C - section & z-axis direction \\
5 & Turning rod & 50 & F - section & y-axis direction \\
\hline
\end{tabular}

$50 \mathrm{~N}$ load is actually the maximum grip force for each finger joint as described in several literatures $[11,12,13]$

\section{REsULtS}

Each part of the new external finger fixator was applied $50 \mathrm{~N}$ of load at a certain direction to determine the maximum deflection and stress distribution. From the results obtained from the simulation shown that there was a very small deflection occurs and the stress distribution was adequate to confront the flexion deformity (Fig. 3 and Fig. 4). The displacement for each part did not exceed $5 \mathrm{~mm}$ of deflection and the maximum stresses that occurred were still below the ultimate tensile strength for a given force as shown in the Table 3 and Table 4 respectively.

Table 3

\begin{tabular}{lc}
\hline \multicolumn{1}{c}{ Components } & $\begin{array}{c}\text { Maximum deflection }(\mathrm{mm}) \\
\text { (in Z-axis direction) }\end{array}$ \\
\hline Distal & 0.414 \\
Rod holder & 0.037 \\
Middle & 0.003 \\
Proximal & 0.511 \\
Turning rod & $5.127^{*}$ \\
\hline
\end{tabular}

*Force is in $\mathrm{Y}$-axis direction

Table 4: Maximum Von mises stress of the new external finger fixator for each component

\begin{tabular}{lc}
\hline Components & $\begin{array}{c}\text { Maximum Mises Stress (MPa) } \\
\text { (in Z-axis direction) }\end{array}$ \\
\hline Distal claw & 1204 \\
Rod claw holder & 237.4 \\
Middle claw & 53.01 \\
Proximal claw & 1313 \\
Turning rod & $3768^{*}$ \\
\hline
\end{tabular}

*Force is in $\mathrm{Y}$-axis direction 


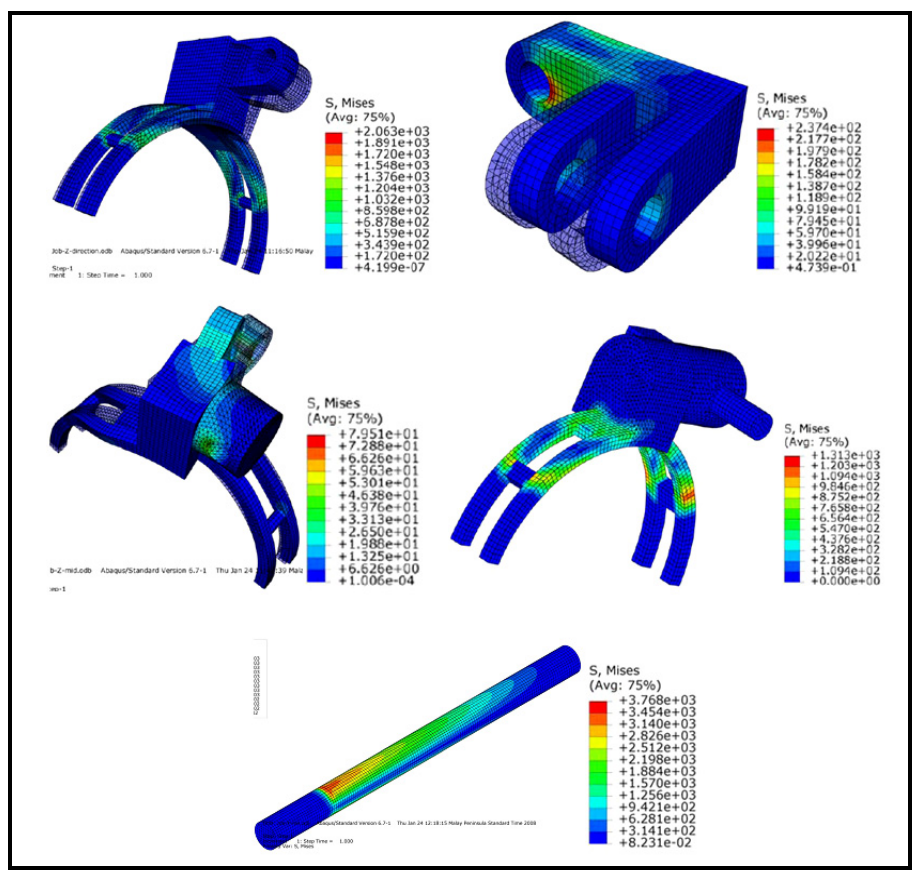

Fig. 3 Deflection at each component of the new external finger fixator (a) Distal part, (b) Rod holder, (c) Middle part, d) Proximal part and (e) Turning Rod

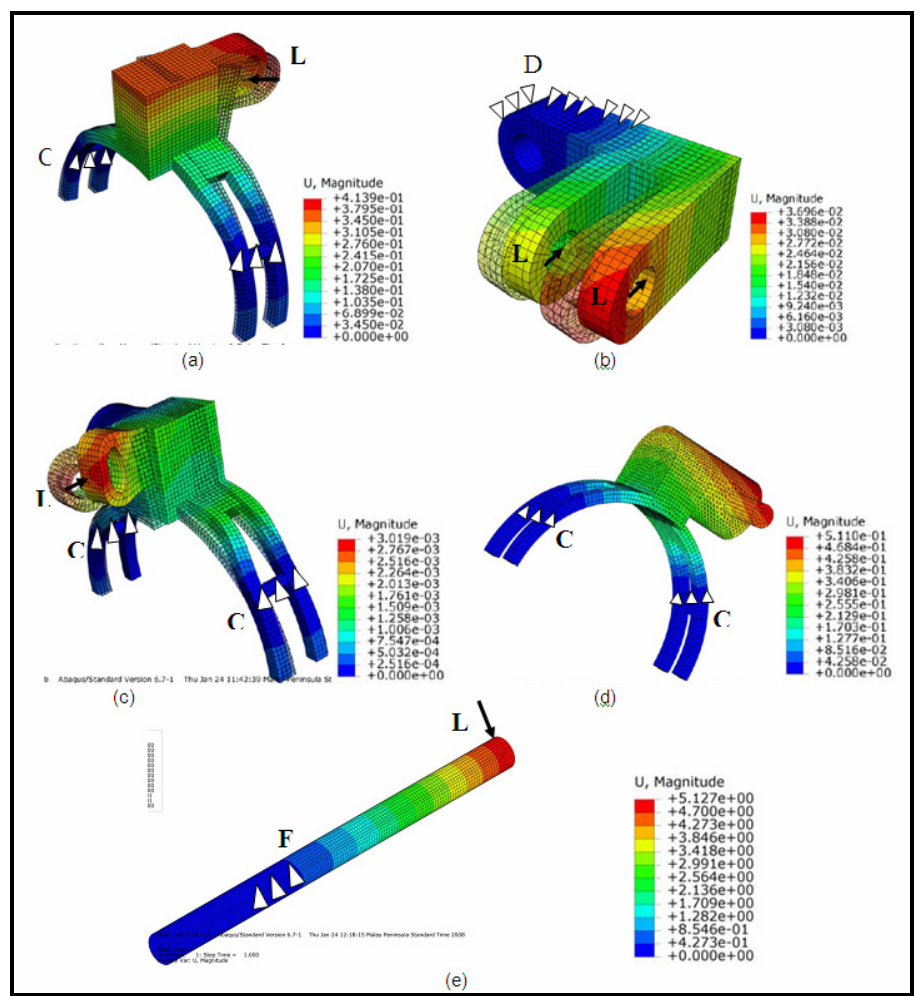

Fig. 4 Stress distribution at each component of the new external finger fixator (a) Distal part, (b) Rod holder, (c) Middle part, d) Proximal part and (e) Turning Rod 


\section{DiSCUSSION AND CONCLUSIONS}

Finite element analysis (FEA) is one of the useful investigative tools that using numerical method for solving many engineering problems such as thermal transfer, fluid flow, structural analysis, and electromagnetic potential. Huiskes and Chao [14] had reviewed that the first application of FEA in orthopaedics was in 1972 [15]. Since then finites elements have proved to be an invaluable tool in orthopaedics design, being widely used in Biomechanics [16, 17] with many different purposes. Finite element analysis was used to investigate the strength and stress distribution to the new external finger fixator after subjected to a maximum load. The analysis was made to each part and the results shows that each component can withstand the maximum finger joint force comparably with the previous testing on cadaver specimen [18]. This research was actually look into the potential in each individual component. However, reality the working system should be in a complete device and this kind of analysis by taking into consideration of other biological factor such as phalangeal bone and soft tissue will be in fourth coming research.

\section{Acknowledgment}

The financial support of the Ministry of Higher Education through Fundamental Research Grant Scheme has made this work possible.

\section{REFERENCES}

1. Maxian TA, Brown TD, Pedersen DR, Callaghan JJ (1996). A sliding-distance-coupled finite element formulation for polyethylene wear in total hip arthroplasty. Journal of Biomechanics 29(5) 687-692.

2. Scifert CF, Brown TD, Lipman JD (1999). Finite element analysis of a novel design approach to resisting total hip dislocation. Clinical Biomechanics. 14(10):697-703.

3. Namba RS, Keyak JH, Kim AS, Vu LP, Skinner HB (1998) Cementless implant composition and femoral stress. A finite element analysis. Clinical Orthopaedics \& Related Research 347:261-267.
4. Vander Sloten J, Hobatho MC, Verdonck P (1998). Applications of computer modelling for the design of orthopaedic, dental and cardiovascular biomaterials. Proc Inst Mech Eng 212(6):489-500.

5. Prendergast PJ (1997). Finite element models in tissue mechanics and orthopaedic implant design. Clinical Biomechanics 12(6) 343-366.

6. Siow Y.S, Ahmad T.S. and Goh S.Y (1999) :Use of a New External Fixator for the Correction of Fixed Flexion Deformity of the Fingers. World Scientific Publishing Company. Hand Surgery 4(2): 167-174.

7. Verdonschot N, Fennis WMM, Kuijs RH, Stolk J, Kreulen CM, Creugers NHJ (2001). Generation of 3D finite element models of restored human teeth using micro-CT techniques. Int $\mathrm{J}$ Prosthodont 14:310 -315.

8. Smith, E.M., Juvinall, R.C., Bender, L.F., and Pearson, J.R (1964) "Role of the finger flexors in rheumatoid deformities of the metacarpophalangeal joints." Arthritis and rheumatism 7:467-480.

9. Chao, E.Y., Opgrande, J.D. and Axmear, F.E., (1976)."Three Dimensional Force Analysis of Finger Joints in Selected Isometric Hand Functions, " J. Biomechanics, 9: 387-396

10. An, k. N., Cooney, W. P., Chao, E. Y. and Linsched, R. L. (1978) Functional strength assessment of normal fingers. In Advances in bioengineering. ASME, New York, 89-90.

11. Kong, Y.K. (2001), Optimum Design of Handle Shape through Biomechanical Modeling of Hand Tendon Forces, Ph.D. dissertation, University Park, PA: Pennsylvania State University,

12. J.W. Lee and K. Rim, (1990) A New Method for Measurement of Finger-phalangeal Force Experimental Mechanics 30 (4) :392-397

13. S. Radhakrishnan and M. Nagaravindra (1993) Analysis of hand forces on health and diseases during maximum isometric grasping of cylinder. Medical \& Biological Engineering \& Computing: 372-376

14. Huiskes R, Chao Eys (1983). A survey of finite element analysis in orthopedic biomechanics: the first decade. J. Biomech16:385-409

15. Brekelmans, W.A.M., Poort, H.W. and Sloof, T.J.H. (1972), "A new method to analyse the mechanical behaviour of skeletal parts", Acta Orthop Scand, 43: 301-317.

16. Mackerle, J. (1992), "Finite and boundary element methods in biomechanics: a bibliography.(1976-1991)", Eng Comput, 9, pp. 403-435.

17. Prendergast, P.J. (1997), "Finite element models in tissue mechanics and orthopaedic implant design", Clinical Biomechanics, 6, pp. 343-366

18. H.S. Abd Rahman, N.A. Abu Osman, S. Yahud, T.S. Tunku Yahya and Ng Eng Seng (2007)A Study Of The External Finger Fixator To Correct Flexion Deformity Journal of Biomechanics, Volume 40, Supplement 2, , Page S183

Author: Herman Shah Abd Rahman
Institute:
$\begin{aligned} & \text { Department of Biomedical Engineering, Faculty of Engi- } \\ & \text { neering, University of Malaya }\end{aligned}$
Street: Jalan Lembah Pantai
City: Kuala Lumpur
Country: Malaysia
Email: herman.shah@yahoo.com.my

